\title{
A cross-sectional study on nutritional status and dietary patterns of children with autism
}

\author{
Md. Nazrul Islam, Farzana Sultana Bari*, Sampad Malakar Chayon, Farhana \\ Yesmin, Sharmin Akter \& Salma Bintey Kashem
}

Department of Public Health Nutrition, Primeasia University, 12 Kemal Ataturk

Avenue, Banani, Dhaka-1213, Bangladesh

\begin{abstract}
Introduction: Literature revealed that individuals with Autism Spectrum Disorders (ASD) experience significantly more feeding problems and obesity compared to their peers. This study was designed to investigate the nutritional status and dietary patterns of children with autism in different age groups in Dhaka city, Bangladesh. Methods: This cross-sectional study was conducted among 193 individuals with ASD. A questionnaire was used as a tool to collect information from the mother of the respondents and anthropometric assessments were conducted by measuring height and weight. The dietary patterns of the respondents were taken using a food frequency questionnaire. Results: The age range of the participants were between $3-18$ years. It was found that $11.9 \%, 19.7 \%$ and $23.3 \%$ of the participants were underweight, overweight and obese, respectively according to Body Mass Index (BMI)-for-age. About $70 \%$ of the respondents had medium Individual Dietary Diversity Score (IDDS). In addition, the association between IDDS and obesity was significantly correlated $(p=0.00)$. Individuals with ASD exhibited similar food preferences across most age groups with little changes. Conclusion: Our study figured out that the prevalence of overweight increased in accordance with age among children with ASD. They have a tendency to prefer likeness and routine in their diet, which expands the tendency to have an imbalanced diet. A dietary guideline including seven food groups should be followed to improve their nutritional status and dietary practices.
\end{abstract}

Keywords: Autism, nutritional status, dietary practice, socioeconomic

\section{INTRODUCTION}

Autism spectrum disorder (ASD) and autism are both general terms for a group of complex disorders in brain development, which may be considered as a life-long disorder that results in varying degrees of difficult social interactions, leading to a wide range of challenging behaviours (Abubakar, Ssewanyana \& Newton, 2016). The symptoms of autism become obvious over the first year (Ozonoff et al., 2008). What is clear, however, is that ASD is largely hereditary, with a higher incidence among boys than among girls (Health Council of the Netherlands, 2009). The prevalence of ASD range between $0.15 \%$ and $0.80 \%$ in Bangladesh. An alarmingly high prevalence of $3 \%$ was reported in Dhaka city and $0.07 \%$ in the rural area (NCDC et al., 2013; Hossain et al., 2017). A Swedish study found that people with

\footnotetext{
*Corresponding author: Farzana Sultana Bari

Assistant Professor, Department of Public Health Nutrition, Primeasia University

Star Tower, 12 Kemal Ataturk Avenue, Dhaka-1213

Fax: 88-02-9820868; Phone: 9821499-501,9821680; Cell: 01726321380; E-mail: farzu_bari@yahoo.

com, farzana.bari@primeasia.edu.bd, farzu.bari80@gmail.com

doi: https: / / doi.org/10.31246/mjn-2019-0126
} 
autism die over 16 years earlier than non-autistic people (Hirvikoski et al., 2016). The average age of death is 36 years, which is around the middle of adulthood (Guan \& Li, 2017). Studies in the United States have found lower rates of autism diagnosis associated with lower socioeconomic status (Kelly et al., 2019).

In children and youth with disability, the risk of obesity is higher and is associated with lower levels of physical activity, inappropriate eating behaviours, and chronic health conditions (Hinckson et al. 2013). Both children and adults with ASD are more likely to be overweight or obese compared with normally developing societies (Safiza et al., 2015; Fortuna et al., 2016).

An individual with ASD experiences significantly more feeding problems when compared to his/her peers (Sharp et al., 2013). Food refusal and introduction of new foods are cited as the most difficult problems in autism (Cornish, 1998). Persons with ASD are significantly more likely to refuse foods based on texture/ consistency, taste/smell, mixtures, brand, and shape (Hubbard et al., 2014). Children with a more limited food repertoire have an inadequate intake of a greater number of nutrients (Bandini et al., 2010). It is generally accepted that autistic youngsters possess unusual eating habits (Williams, Dalrymple \& Neal, 2000), which may be resulted from oral sensory sensitivity (Chistol et al., 2018). In addition, their dietary patterns, food preferences and food stigma aggravate their poor nutritional condition, both in terms of under- and over-nutrition. In accordance, our study has been designed to assess the dietary patterns and nutritional status of individuals with autism in order to get an idea of the overall changes in nutritional status and food preferences according to their age.

\section{MATERIALS AND METHODS}

\section{Study design, period and setting}

A cross-sectional study was conducted in six conveniently accessible autism special institutions in Dhaka North City corporation area between the period of January to December 2018.

\section{Participants}

A sampling frame of 470 individuals from six autism special institutions was constructed. Among them, 193 student's information were collected randomly following inclusion criteria, which were individual with autism who was regular in visiting a particular institution for study or treatment purposes, and whose mother or caregiver had agreed to give an interview when selected as a study sample.

\section{Procedures}

A semi-structured questionnaire containing both closed- and open-ended questions were used to collect quantitative information. The questionnaire was used to gather information regarding socioeconomic status and dietary practices of individuals with autism. Height and weight were measured using standard procedures. A pilot study was carried out in a similar institution in Dhaka North City.

\section{Measures}

Nutritional status was assessed by measuring height and weight, which was associated with their age. The weight of the respondents was measured (to the nearest $0.1 \mathrm{~kg}$ ) using a standardised digital weighing machine. They were barefooted, in minimum clothing, empty bladder and stomach when being weighed. Oedema was checked before taking weight. The height of the respondents was measured (to the nearest $0.1 \mathrm{~cm}$ ) using a locally made 
standardised height scale. Nutritional status was evaluated based on the World Health Organization (WHO) guidelines (WHO, 2009) for the calculation of $z$-score (3-5 years), while Emergency Nutritional Assessment (ENA) was used to calculate the $z$-score of participants below five years of age. The Center for Disease Control (CDC) and Prevention growth chart for 2-20 years in respective of sex and its online calculator were used to calculate the BMI-for-age percentiles, where overweight was defined as $\geq 85$ th percentile, obesity as $\geq 95$ th percentile, and underweight as $<5$ th percentile (Center for Disease Control \& Prevention, 2014).

Dietary evaluation was measured by using a questionnaire of 16 food groups (Kennedy et al., 2011), which was later converted into lesser food groups based on the anticipation of the study. The frequency of the Individual Dietary Diversity Score (IDDS) was calculated based on the Food and Agriculture Organization (FAO) 2011 guidelines using the frequency of consumption of nine different food groups in the last 24 hours. Value "one" was given for having the food and "zero" for not having the food. The sum of IDDS categorised respondents into three categories: low (score 0-3), medium (score 4-5) and high (score 6-9) (Kennedy et al., 2011).

Socioeconomic status was measured by a quintile method, where the first quintile was categorised as lowincome group, while the second to fourth quintiles and the fifth quintile were considered as middle- and higherincome groups, respectively.

\section{Data analysis}

All data collected from the respondents were compiled, tabulated and analysed according to the objectives of the study. Statistical Package for Social Sciences (SPSS version 22) was used to classify categorical variables and continuous variables in response to the research aims. Frequency distribution, percentage, and descriptive statistics including mean, standard deviation (SD) were calculated. Chi-square test was performed to test for significant associations and a $p$ value of $<0.05$ was considered as statistical significance. Microsoft Excel was used to analyse the IDDS scores and for graphical presentation.

\section{Ethical consideration}

This study was approved by Primeasia University, Dhaka, Bangladesh. Written consent was obtained from the participants. All the respondents were informed about the aim of the study. Confidentiality of personal information was strictly maintained.

\section{RESULTS}

\section{Socio-demographic status}

A total number of 193 individuals with ASD were studied and their sociodemographic status are shown in Table 1. The participation ratio for males and females was 2.5:1. A higher number of respondents came from medium sized families (4-7 members) and about $76.2 \%$ have been raised in a nuclear family. In addition, $83.4 \%$ of fathers and $67.9 \%$ of mothers were educated at the graduate and postgraduate levels. On the other hand, the rates of illiteracy were of the same order of magnitude among parents. Among the total sample, $67.4 \%$ of fathers were involved in business and non-government services. However, $90.2 \%$ of mothers were housewife. This study expressed that $70.9 \%$ of persons with autism were the first born of the family. It is remarkable that $87.0 \%$ of mothers were the caregiver of their child at home. The table also depicts that about $14.5 \%$ of the participants were from the low-income group, while $45.6 \%$ and $39.9 \%$ belonged to the middleand high-income groups, respectively. Families had to spend $23.2 \%$ of their 
Table 1. Socio-demographic characteristics of children with autism

\begin{tabular}{|c|c|c|c|}
\hline Characteristics & $n$ & $\%$ & Mean \\
\hline Age group (years) & & & \pm 8.5 (years) \\
\hline $3-<5$ & 31 & 15.4 & \\
\hline $5-<10$ & 109 & 54.2 & \\
\hline $10-<18$ & 53 & 26.4 & \\
\hline \multicolumn{4}{|l|}{ Sex } \\
\hline Male & 138 & 71.5 & \\
\hline Female & 55 & 28.5 & \\
\hline \multicolumn{4}{|l|}{ Father's Occupation } \\
\hline Govt. Service & 12 & 6.2 & \\
\hline Non-Govt. Service and business & 130 & 67.4 & \\
\hline Others & 51 & 26.4 & \\
\hline \multicolumn{4}{|l|}{ Mother's Occupation } \\
\hline Govt. Service & 4 & 2.1 & \\
\hline Non-Govt. Service & 15 & 7.7 & \\
\hline Housewife & 174 & 90.2 & \\
\hline \multicolumn{4}{|l|}{ Education level of fathers } \\
\hline Graduate and Post-Graduate & 161 & 83.4 & \\
\hline Secondary and Higher Secondary level & 22 & 11.3 & \\
\hline Primary level and illiterate & 10 & 5.1 & \\
\hline \multicolumn{4}{|l|}{ Educational level of Mothers } \\
\hline Graduate and Post-Graduate & 131 & 67.9 & \\
\hline Secondary and Higher Secondary level & 49 & 25.4 & \\
\hline Primary level and illiterate & 13 & 6.7 & \\
\hline \multicolumn{4}{|l|}{ Caregiver at home } \\
\hline Mother & 168 & 87.0 & \\
\hline Grandmother/Father/Others & 25 & 13.0 & \\
\hline \multicolumn{4}{|l|}{ Birth order } \\
\hline First born & 137 & 70.9 & \\
\hline Second born & 48 & 24.9 & \\
\hline Third or fourth & 8 & 4.2 & \\
\hline \multicolumn{4}{|l|}{ Types of family } \\
\hline Nuclear family & 147 & 76.2 & \\
\hline Joint family & 46 & 23.8 & \\
\hline \multicolumn{4}{|l|}{ Income groups } \\
\hline Low income group & 28 & 14.5 & \\
\hline Middle income group & 88 & 45.6 & \\
\hline Higher income group & 77 & 39.9 & \\
\hline \multicolumn{4}{|l|}{ Mean income (BDT/Month) } \\
\hline Low income group & & & 29171 \\
\hline Middle income group & & & 65600 \\
\hline Higher income group & & & 144331 \\
\hline \multicolumn{4}{|l|}{ Mean expenditure (BDT/Month) } \\
\hline Low income group & & & 25723 \\
\hline Middle income group & & & 54801 \\
\hline Higher income group & & & 93219 \\
\hline \multicolumn{4}{|l|}{$\begin{array}{l}\text { Mean Expenditure on autistic child } \\
\text { (education, treatment, others) (BDT/Month) }\end{array}$} \\
\hline Low income group & & & 6793 \\
\hline Middle income group & & & 15709 \\
\hline Higher income group & & & 25466 \\
\hline
\end{tabular}


total income as the cost for their child in the low-income group, $23.9 \%$ and $17.6 \%$ in the middle- and high-income groups, respectively.

\section{Nutritional status}

The overall nutritional status of the participants was assessed according to BMI-for-age percentile. A total of 31 children aged between 3 to $<5$ years were selected to be assessed according to three anthropometric indices - weightfor-age, height-for-age and weight-forheight $z$-scores, which were referred to for underweight, stunting and wasting, respectively.

Table 2 represents the weight-forage $z$-scores, where $71.0 \%$ were normal according to their age. The prevalence of underweight was $3.1 \%$ and overweight was $25.9 \%$ among children with ASD. Height-for-age $z$-score indicated that the frequency of stunting among the participants was only $3.2 \%$, while $80.6 \%$ were normal according to their age. This table showed the occurrence of wasting in only $6.9 \%$, while $62.1 \%$ were normal and $31.0 \%$ were overweight according to their height and weight. Moreover, Table 2 also conveyed that underweight among children with autism was $11.9 \%$. Likewise, overweight and obesity were $19.7 \%$ and $23.3 \%$, respectively. A total of $45.1 \%$ of children with autism were healthy according to their age and sex. It has been observed that overweight increased gradually with age.

\section{Dietary evaluation}

A dietary assessment is a comprehensive evaluation of a person's food intake. Nutritional history and current dietary intake data provide information on a population, group or individual's nutritional status to identify potential nutritional problems.

In this study, the mothers reported that their children liked to ingest solid

Table 2. Nutritional status of individuals with autism

\begin{tabular}{|c|c|c|c|c|c|c|c|c|}
\hline \multirow[t]{2}{*}{$\begin{array}{l}\text { Anthropometric } \\
\text { Indicators }\end{array}$} & \multicolumn{2}{|c|}{$\begin{array}{c}\text { Underweight } \\
(<-2 S D / \\
B M I<18.5 / \\
<5^{\text {th }} \text { Percentile) }\end{array}$} & \multicolumn{2}{|c|}{$\begin{array}{c}\text { Normal } \\
( \pm 2 S D / B M I \\
18.5-24.99 / 5^{\text {th }} \\
-<85^{\text {th }} \text { Percentile) }\end{array}$} & \multicolumn{2}{|c|}{$\begin{array}{c}\text { Overweight } \\
(>+2 S D / B M I \\
25-29.99 / 85^{\text {th }} \\
-<95^{\text {th }} \text { Percentile) }\end{array}$} & \multicolumn{2}{|c|}{$\begin{array}{c}\text { Obese } \\
(B M I \geq 30 / \\
\geq 95^{\text {th }} \\
\text { Percentile) }\end{array}$} \\
\hline & $n$ & $\%$ & $n$ & $\%$ & $n$ & $\%$ & $n$ & $\%$ \\
\hline $\begin{array}{l}\text { Weight-for-age } z \text { - score } \\
\text { (underweight), } n=31\end{array}$ & 1 & 3.1 & 22 & 71.0 & 8 & 25.9 & 0 & 0 \\
\hline $\begin{array}{l}\text { Height-for-age } z \text {-score } \\
\text { (Stunting), } n=31\end{array}$ & 1 & 3.2 & 25 & 80.6 & 5 & 16.2 & 0 & 0 \\
\hline $\begin{array}{l}\text { Weight-for-height } z \text {-score } \\
\text { (wasting), } n=29\end{array}$ & 2 & 6.9 & 18 & 62.1 & 9 & 31.0 & 0 & 0 \\
\hline $\begin{array}{l}\text { Overall nutritional status } \\
\text { based on BMI-for-age, } \\
n=193\end{array}$ & 23 & 11.9 & 87 & 45.1 & 38 & 19.7 & 45 & 23.3 \\
\hline \multicolumn{9}{|l|}{$\begin{array}{l}\text { BMI-for-age, in different } \\
\text { age groups }\end{array}$} \\
\hline $3-<5$ yrs. $n=31$ & 3 & 9.7 & 18 & 58.1 & 2 & 6.5 & 8 & 25.7 \\
\hline $5-<10$ yrs. $n=109$ & 14 & 12.8 & 46 & 42.2 & 21 & 19.3 & 28 & 25.7 \\
\hline $10-<18$ yrs. $n=53$ & 6 & 11.3 & 23 & 43.4 & 15 & 28.3 & 9 & 17.0 \\
\hline
\end{tabular}




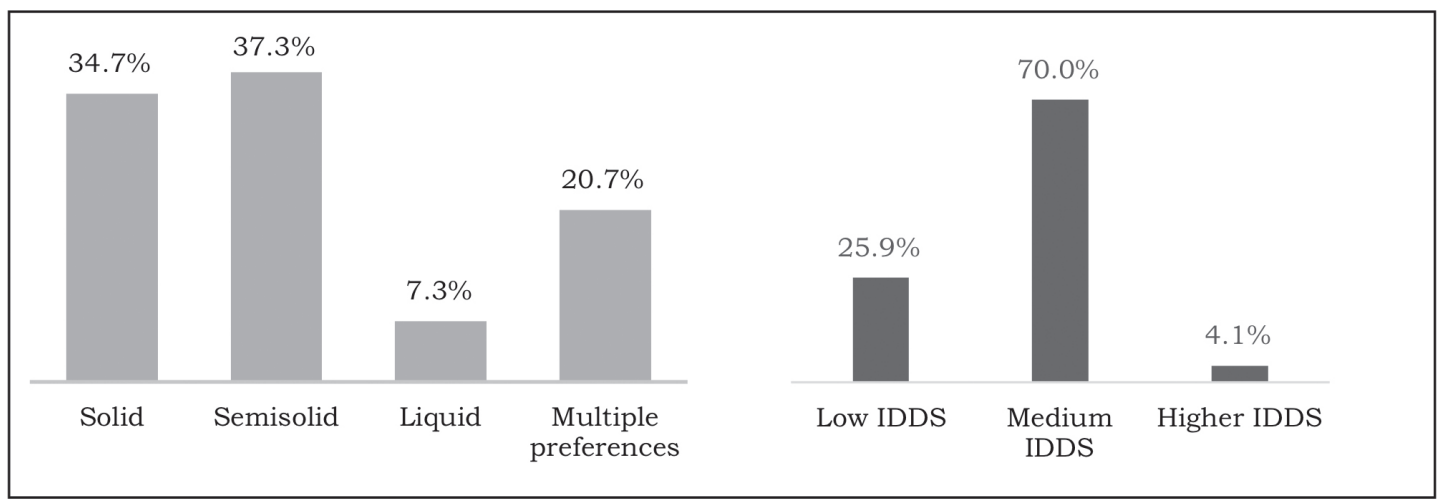

Figure 1. Preferences of food consistency and individual dietary diversity score (IDDS) among individuals with autism

and semi-solid foods. It was found that $34.7 \%$ and $37.4 \%$ of children preferred solid and semi-solid foods. Nevertheless, only $7.3 \%$ of children liked to consume liquid foods. Besides, $20.7 \%$ of individuals had multiple preferences on different consistency of foods. It was found that more than two-thirds $(70 \%)$ of the study participants had medium IDDS, while $25.9 \%$ had low and only
$4.1 \%$ had high IDDS, respectively. In addition, the association between IDDS and obesity (BMI) was significant $(p<0.002)$ (Figure 1).

Interestingly, children with ASD have a strong liking and disliking of foods. This study revealed that cerealbased products and fats and oil were consumed by all age groups every day. In contrast, nuts and oil seeds were

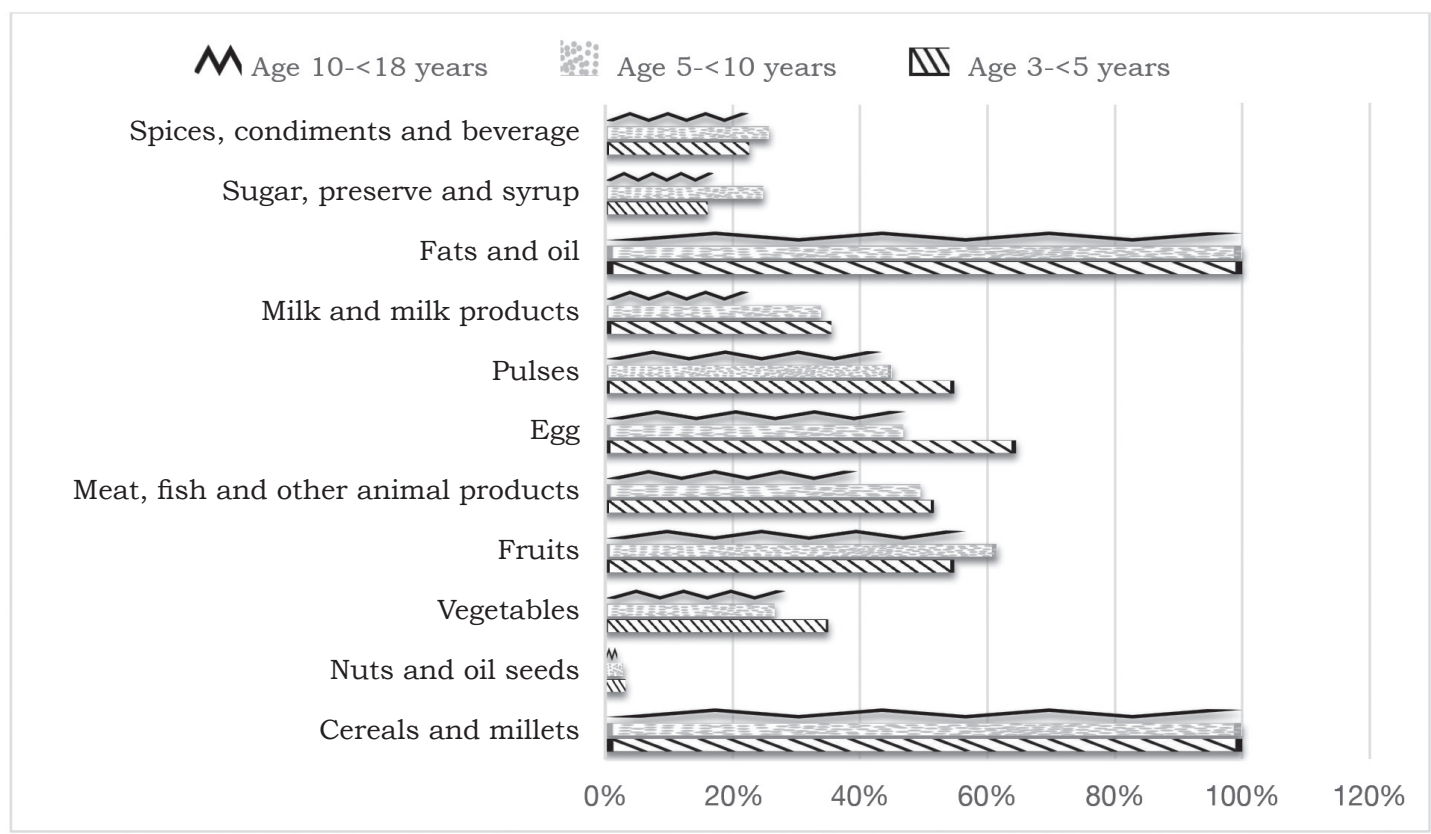

Figure 2. Food group preferences among individuals with autism according to different age groups 
the least preferred foods. Milk and milk products, as well as egg consumption reduced comparatively with the increase in age. The consumption of other food groups did not change significantly with age.

Table 3 shows the association between nutritional status with different variables. The data represents that there were strong associations between parent's education level, income, and low birth weight with underweight. The table also revealed that income level and IDDS had a positive relationship with obesity.

\section{DISCUSSION}

The socio-demographic data of this study indicated that there were more male autistic participants compared to females. Almost two third of the individuals were first born, which was similar with that of another study conducted in the same region (Hasnain \& Akter, 2014). The present study revealed that institutional education was high among the parents of individuals with autism and positively associated with undernutrition, although a previous study proved that there was no association between parent's education and the development of autism in children (Larsson et al., 2005). The mean income of all three income groups (low, middle and high) was much higher than the per capita income of Bangladesh, which was also reflected in a 2017 study (Safa \& Islam, 2017). The present study showed that around one-fourth of the total family income was spent on raising autistic children. Nevertheless, prior research has shown that the annual loss due to having a child with autism is about $14 \%$ of the total family income. This study also showed that almost $2 / 3$ of children belonged to a nuclear and medium-size family. Likewise, a separate study reported that majority of their samples $(87 \%)$ were from nuclear families (Hasnain \& Akter, 2014).

Good nutrition is one of the leading factors for attaining a healthy life. Undernourishment was not predominant among our study population. On the other hand, this study found that overweight was gradually increased with age in autistic children. Conversely,

Table 3. Association of different variables with nutritional status (chi-squire test)

\begin{tabular}{lcccc}
\hline Factors & $\begin{array}{c}\text { Underweight } \\
\text {-value }\end{array}$ & $\begin{array}{c}\text { Healthy } \\
\text {-value }\end{array}$ & $\begin{array}{c}\text { Overweight } \\
p \text {-value }\end{array}$ & $\begin{array}{c}\text { Obesity } \\
p \text {-value }\end{array}$ \\
\hline Age (Mean = 103 months, SD = 41 months) & 0.11 & 0.30 & 0.80 & 0.43 \\
Sex (Male 71.5\%, Female 28.5\%) & 0.78 & 0.56 & 0.63 & 0.65 \\
Income level (Mean = 91955 BDT, & $0.00^{* *}$ & 0.55 & 0.73 & $0.02^{*}$ \\
SD = 62280 BDT) & & & & \\
Fathers education & $0.00^{* *}$ & 0.10 & $0.01^{*}$ & 0.15 \\
Mothers education & $0.00^{* *}$ & $0.00^{* *}$ & $0.03^{*}$ & 0.32 \\
Family types (Joint 23.8\%, Nuclear 76.2\%) & 0.78 & 0.35 & 0.65 & 0.19 \\
Premature baby (<37 weeks of pregnancy, & $0.04^{*}$ & 0.83 & 0.76 & 0.37 \\
Yes 20.2\%) & & & & \\
Low birth weight (<2.5 kg, Yes 24.9\%) & $0.02^{*}$ & 0.64 & 0.14 & 0.38 \\
Exclusive breast feeding (Up to six months, & 0.79 & 0.68 & 0.25 & 0.42 \\
Yes 56.5\%) & & & & \\
IDDS (Mean 4.37, SD \pm 1.34$)$ & 0.20 & 0.40 & 0.80 & $0.00^{* *}$ \\
\hline
\end{tabular}

*Correlation is significant at $p<0.05 ;{ }^{* *}$ Significant at $p<0.01$ 
a similar study revealed that obesity was higher among the younger age groups (Curtin et al., 2005). The present study also found that family income and parent's education had a positive association with the nutritional status of participants, which had already been proven by a previous study (Skoufias, 1999).

In the current study, it was found that a greater number of children preferred semi-solid foods, which may have been resulted from oral sensory sensitivity (Chistol et al., 2018). Cereals and fats and oils were the most preferred food groups. Unfortunately, intake of proteinenriched foods gradually decreased among them. Children aged between 5 and $<10$ years old consumed higher amounts of sugar and syrup compared to other age groups. This study also reported that almost two-third of the respondents had medium IDDS. An excellent statistical association was found between IDDS and obesity, which indicated that dietary diversity score had a great impact on nutritional status. Selective eating and food aversion were also found among children with ASD. Children with ASD tend to prefer the same food repeatedly, which can result in a severely imbalanced diet (Barnhill et al., 2015). Research conducted by Evans et al. (2012) has found that children with ASD consume more sweetened beverages and snacks, and fewer fruits and vegetables than typically developing children, which resembled our study outcomes. The study findings indicated that both positive and negative malnutrition are quite significant with an imbalanced diet.

\section{CONCLUSION}

Our study showed that the prevalence of overweight and obesity over the years among the respondents with ASD was pretty alarming that it is reasonably worthy to be further investigated, preferably in longitudinal studies. Though our data did not contradict existing information dealing with the dietary habits of children with autism, long-term nutritional intervention including detailed dietary guidelines and awareness programmes play a fundamental role in the correction of inappropriate feeding habits and eventually improving the nutritional status of children with autism.

\section{Acknowledgment}

We would like to express our respect and sincere gratitude to our academic supervisor, cosupervisor and other teachers for their counsel and encouragement. We evolve respect to the Institute Authority and respondents for giving us permission to collect information from them. Finally, our special thanks to our parents and friends who supported us for conducting this study.

\section{Author's contribution}

MNI and FSB, contributed to the conception, design, acquisition, analysis and interpretation of data, also drafted and revised the manuscript; SMC, FY, SA and SBK, helped with conception and data acquisition. All authors approved the final manuscript.

\section{Competing interests}

The authors declare that they have no competing interests.

\section{References}

Abubakar A, Ssewanyana D \& Newton CR (2016). A systematic review of research on autism spectrum disorders in sub-Saharan Africa. Behav Neurol 2016:1-14.

Bandini LG, Anderson SE, Curtin C, Cermak S, Evans EW, Scampini R \& Must A (2010). Food selectivity in children with autism spectrum disorders and typically developing children. $J$ Pediatr 157(2):259-264.

Barnhill K, Gutierrez A, Marti SN \& Hewitson L (2015). Analysis of dietary intake in children with autism spectrum disorder. AutismOpen Access 5(3):154. doi: 10.4172/21657890.1000154 .

Center for Disease Control and prevention (2014). Division of Nutrition, Physical Activity, and Obesity. From https://www.cdc.gov/nccdphp/ dnpao/growthcharts/training/bmiage/page4. html. [Retrieved May 9 2014] 
Chistol LT, Bandini LG, Must A, Phillips S, Cermak SA \& Curtin C (2018). Sensory sensitivity and food selectivity in children with autism spectrum disorder. $J$ Autism Dev Disord (2):583-91.

Cornish E (1998). A balanced approach towards healthy eating in autism. J Hum Nutr Diet 11(6): 501-509.

Curtin C, Bandini LG, Perrin EC, Tybor DJ \& Must A (2005). Prevalence of overweight in children and adolescents with attention deficit hyperactivity disorder and autism spectrum disorders: a chart review. BMC Pediatr 5(1):48.

Evans EW, Must A, Anderson SE, Curtin C, Scampini R, Maslin M \& Bandini L (2012). Dietary patternss and body mass index in children with autism and typically developing children. Res Autism Spectr Disord 6(1):399405.

Fortuna RJ, Robinson L, Smith TH, Meccarello J, Bullen B, Nobis K \& Davidson PW (2016). Health conditions and functional status in adults with autism: a cross-sectional evaluation. J Gen Intern Med 31(1):77-84.

Guan J \& Li G (2017). Injury mortality in individuals with autism. Am J Public Health 107(5):791-793.

Hasnain MG \& Akter M (2014). The relation of socioeconomic factors with autism among children: a study in an urban area of Bangladesh. $J$ Pioneer Med Sci 4(1):11-13

Health Council of the Netherlands, Gezondheidsraad (2009). Autism spectrum disorders: A lifetime of difference. The Hague: Health Council of the Netherlands/ Gezondheidsraad (GR). 2009/09E. 2009. From https://www.healthcouncil.nl/documents / advisory-reports / 2009/07/16/autismspectrum-disorders-a-lifetime-of-difference [Retrieved August 16 2020].

Hinckson EA, Dickinson A, Water T, Sands M \& Penman L (2013). Physical activity, dietary habits and overall health in overweight and obese children and youth with intellectual disability or autism. Res Dev Disabil34(4):11701178.

Hirvikoski T, Mittendorfer-Rutz E, Boman M, Larsson H, Lichtenstein P \& Bölte S (2016). Premature mortality in autism spectrum disorder. Br J Psychiatry 208(3):232-238.

Hossain MD, Ahmed HU, Jalal Uddin MM, Chowdhury WA, Iqbal MS, Kabir RI \& Sarker M (2017). Autism spectrum disorders (ASD) in South Asia: A systematic review. BMC Psychiatry 17(1):281.
Hubbard KL, Anderson SE, Curtin C, Must A \& Bandini LG (2014). A comparison of food refusal related to characteristics of food in children with autism spectrum disorder and typically developing children. J Acad Nutr Diet 114(12):1981-1987.

Kelly B, Williams S, Collins S, Mushtaq F, MonWilliams M, Wright B \& Wright J (2019). The association between socioeconomic status and autism diagnosis in the United Kingdom for children aged 5-8 years of age: Findings from the Born in Bradford cohort. Autism 23(1):131140 .

Kennedy G, Ballard T, Dop MC \& European Union (2011). Guidelines for measuring household and individual dietary diversity. Food and Agriculture Organization of the United Nations, Rome.

Larsson HJ, Eaton WW, Madsen KM, Vestergaard M, Olesen AV, Agerbo E, Schendel D, Thorsen P \& Mortensen PB (2005). Risk factors for autism: perinatal factors, parental psychiatric history, and socioeconomic status. Am J Epidemiol 161(10):916-25.

NCDC, RCHCIB, BMRC \& DSH (2013). Survey of Autism and Neurodevelopmental Disorders in Bangladesh. Non Communicable Diseases Control (NCDC) Programme, DGHS, MOHFW, Revitalization of Community Health Care Initiatives in Bangladesh (RCHCIB), Ministry of Health and Family Welfare (MOHFW); Bangladesh Medical Research Council (BMRC), MOHFW; Department of Pediatric Neuroscience, Dhaka Shishu Hospital, Dhaka, Bangladesh.

Ozonoff S, Heung K, Byrd R, Hansen R \& HertzPicciotto I (2008). The onset of autism: patterns of symptom emergence in the first years of life. Autism Res 1(6):320-328.

Safa F \& Islam MN (2017). Health related quality of life in children with autism spectrum disorder in Bangladesh. IMC J Med Sci 11(2): 4044

Safiza MNN, Abdul Aziz NS, Siew Man C, Ambak R, Azahadi OM (2015). Nutritional Status of Children with Autism Spectrum Disorders, Cerebral Palsy and Down Syndrome: A Scoping Review. Open Access $J$ Sci Technol 3(2015):101174. doi: https://doi. org/10.11131/2015/101174

Sharp WG, Berry RC, McCracken C, Nuhu NN, Marvel E, Saulnier CA \& Jaquess DL (2013). Feeding problems and nutrient intake in children with autism spectrum disorders: A meta-analysis and comprehensive review of the literature. J Autism Dev Disord 43(9):21592173. 
Skoufias E (1999). Parental education and child nutrition in Indonesia. Bull Indones Econ Stud 35(1):99-119.

WHO (2009). WHO Child Growth Standards and the Identification of Severe Acute Malnutrition in Infants and Children. A Joint Statement by the World Health Organization and the United Nations Children's Fund. Geneva: World Health Organization. From: http://www.ncbi.nlm.nih. gov/books/NBK200775/ [Retrieved August 16 2020].

Williams PG, Dalrymple N \& Neal J (2000). Eating habits of children with autism. Pediatr Nurs 26(3):259-64. 